\title{
The functional cytology of Bonamia sp. (Haplosporidia) infecting oysters Tiostrea chilensis: an ultracytochemical study
}

\author{
P. M. Hine, B. Wesney \\ Fisheries Research Centre, Ministry of Agriculture and Fisheries, PO Box 297, Wellington, New Zealand
}

\begin{abstract}
Bonamia sp., a serious pathogen of oysters Tiostrea chilensis, was studied using the zinc iodide-osmium tetroxide technique (ZIO), the imidazole-osmium technique for lipids (IM), and reactivity for acid phosphatases $[\beta$-glycerophosphatase ( $\beta$-GPase), cytidine monophosphatase at pH 5.0 (CMPase 5.0) and pH 2.7 (CMPase 2.7), thiamine pyrophosphatase (TPPase)], and $\beta$-galactosidase to try and determine the function of cytoplasmic organelles. ZlO reacted with the nuclear membrane, Golgi, endoplasmic reticulum (ER), cytoplasmic vesicles, and variably with putative phagosomes, the mitochondrial matrix, haplosporosomes and multivesicular bodies, but not lipoid bodies. IM strongly labelled lipoid bodies, and lipids in the nuclear membrane, ER except anastomosing ER (aER) and mitochondrial membranes and cristae, but was weak in aER and on haplosporosomes. $\beta$-GPase occurred in the nuclear membrane, some elements of ER, Golgi and mitochondria, and in lipoid bodies. CMPase 5.0 was variable in Golgi and ER, but was stronger at $\mathrm{pH} 2.7$ and occurred in the nuclear membrane. TPPase only occurred in a single Golgi cisterna, or very weakly in a few lipoid bodies. $\beta$-galactosidase was rarely seen, and only within Golgi. As there was considerable metabolism of unsaturated lipids and little hydrolytic enzyme content, it was concluded that Bonamia sp. may synthesise lipids from triglycerides hydrolysed by haemocyte enzymes, reducing the need for parasite hydrolytic enzymes.
\end{abstract}

KEY WORDS: Bonamia sp. · Organelle function · Hydrolytic enzymes · Lipid metabolism

\section{INTRODUCTION}

Elucidation of the fine structure of an organism is of limited value if the functions of its constituent parts are unknown. Protistans have some organelles similar to those of higher eukaryotes, and ontogenetic, although not necessarily functional, homology can be assumed. Other organelles are restricted to protistans and their functions are unknown. Such an organelle is the haplosporosome of haplosporidians, which appears to be formed from interaction of putative nuclear material with Golgi-like arrays and endoplasmic reticulum (ER) (Perkins 1979, Hine 1992, Hine \& Wesney 1992). The spherulosome of haplosporidian spores may also form haplosporosomes, and be homologous to the Golgi apparatus (Desportes \& Nashed 1983). Haplosporosomes contain periodate-reactive complex carbohydrates (Perkins 1976), and have a protein matrix, an external membrane of glycoprotein, and an internal membrane of lipid (Azevedo \& Corral 1985). Other organelles, called lipoid or dense bodies, are formed from concentric arrays of smooth endoplasmic reticulum (Hine 1992), and could contain acid phosphatase (Hervio et al. 1991, Hine 1992).

This study was to determine whether Bonamia sp. has a Golgi-endoplasmic reticulum-lysosome system similar to that of higher eukaryote cells (Kornfeld \& Mellman 1989), and to examine the functions of this system. Golgi-endoplasmic reticulum relationships were studied using the zinc iodide-osmium tetroxide (ZIO) technique, and lipid distribution using an imidazole-buffered osmium technique (Benchimol \& de Souza 1985). $\beta$-glycerophosphatase, cytidine monophosphatase (CMPase) and $\beta$-galactosidase were used as lysosomal enzyme markers. CMPase was selected because it stains trans-Golgi networks on the trans aspect of Golgi in higher animals (Hermo et al. 1991), and CMPase and $\beta$-galactosidase as they have been 
reported from B. ostreae (Hervio et al. 1991, Hervio 1992). Thiamine pyrophosphatase was used because it selectively stains Golgi trans cisternae in higher animals (Hermo et al. 1991).

\section{MATERIALS AND METHODS}

From December 1992 to August 1993, the hearts of 226 oysters Tiostrea chilensis infected with Bonamia sp., as determined from heart imprints (Hine \& Wesney 1992), were fixed for the following techniques.

Zinc iodide-osmium tetroxide (ZIO) for subcellular structures (Pellegrino de Iraldi 1977). Fixation: $2.5 \%$ glutaraldehyde in $0.22 \mu \mathrm{m}$ filtered seawater (FSW) for $1 \mathrm{~h}$ at $18^{\circ} \mathrm{C}$. Wash: FSW. Process as described by Benchimol \& de Souza (1985). Incubate control grids for 30 min at $18^{\circ} \mathrm{C}$ with $1 \mathrm{mM}$ dithiotreitol (DTT) dissolved in 0.1M Tris buffer ( $\mathrm{pH} \mathrm{6.8)} \mathrm{before} \mathrm{ZIO} \mathrm{incuba-}$ tion (Benchimol \& de Souza 1985)

Imidazole-buffered osmium tetroxide (IM) for lipids (Angermüller \& Fahimi 1982). Fixation: $2.5 \%$ glutaraldehyde in FSW. Wash: $2 \times$ FSW. Post-fixation: $2 \% \mathrm{OsO}_{4}$ in $0.1 \mathrm{M}$ imidazole (IM) buffer, pH 7.5, for 30 to 60 min at $18^{\circ} \mathrm{C}$ (Benchimol \& de Souza 1985).

Techniques used for enzyme cytochemistry were as described below, with 2 routine modifications: (1) $0.22 \mu \mathrm{m}$ FSW was used as buffer for glutaraldehyde fixation, and for the 2 subsequent washes and the second wash after incubation, while buffers specified in published techniques were used for incubation and the first post-incubation wash; and (2) grids were post-fixed in $1 \% \mathrm{OsO}_{4}$ for $20 \mathrm{~min}$ at $18^{\circ} \mathrm{C}$ to minimise osmophilia.

$\beta$-Glycerophosphatase ( $\beta$-GPase) (Robinson \& Karnovsky 1983$)$. Fixation: 1 h at $4^{\circ} \mathrm{C}$ in $2 \%$ glutaraldehyde. Wash: $2 \times \mathrm{FSW}$. Incubation: $30 \mathrm{~min}$ at $37^{\circ} \mathrm{C}$ in Gomori medium [ $1 \mathrm{mM} \beta$-glycerophosphate, $2 \mathrm{mM}$ cerium chloride, $5 \%$ sucrose, $0.1 \mathrm{M} \mathrm{Na}$ acetate- $\mathrm{HCl}$ buffer $(\mathrm{pH} 5.0)]$, change incubation solution with fresh solution and incubate for further $30 \mathrm{~min}$, first post-incubation wash with $0.1 \mathrm{M} \mathrm{Na}$ cacodylate buffer with $5 \%$ sucrose.

Cytidine monophosphatase (CMPase) (Hervio et al. 1991). Fixation: 1 h at $4^{\circ} \mathrm{C}$ in $2 \%$ glutaraldehyde.
Wash: $2 \times$ FSW. Incubation: $90 \mathrm{~min}$ at $37^{\circ} \mathrm{C}$ in Novikoff's medium (25 mg cytidine 5'-monophosphate, $12 \mathrm{ml} \mathrm{DH} \mathrm{DH}_{2} \mathrm{O}, 3 \mathrm{ml} 1 \%$ lead nitrate, $10 \mathrm{ml} \mathrm{Na}$ acetate buffer, $20 \%$ sucrose), first post-incubation wash with $0.05 \mathrm{M} \mathrm{Na}$ acetate buffer. Incubation and first postincubation washes were carried out at pH 2.7 (CMPase 2.7) or the usual pH 5.0 (CMPase 5.0).

Thiamine pyrophosphatase (TPPase) (Robinson \& Karnovsky 1983). Fixation: 1 h at $4^{\circ} \mathrm{C}$ in $2 \%$ glutaraldehyde. Wash: $2 \times$ FSW. Incubation: $1 \mathrm{~h}$ at $37^{\circ} \mathrm{C}$ in $1 \mathrm{mM}$ thiamine pyrophosphate chloride, $2 \mathrm{mM}$ manganese chloride, $2 \mathrm{mM}$ cerium chloride, $0.1 \mathrm{M}$ Trismaleate buffer ( $\mathrm{pH} 7.2$ ) to make $100 \mathrm{ml}$ and $20 \%$ sucrose; first post-incubation rinse in Tris-maleate buffer.

$\beta$-Galactosidase (Rhodes \& Blom 1986). Fixation: 30 min at $4^{\circ} \mathrm{C}$ in $1.25 \%$ glutaraldehyde. Wash $2 \times$ FSW. Incubation: $5 \mathrm{~h}$ at $37^{\circ} \mathrm{C}$ in a medium of $8 \mathrm{mg} 5$ bromo-4-chloro-3-indolyl- $\beta$-D-galactopyranoside, $2 \mathrm{ml}$ dimethyl formamide, $32 \mathrm{mg}$ spermidine tri-hydrochloride, $2 \mathrm{ml} 0.085 \% \mathrm{NaCl}_{1} 12 \mathrm{ml} 0.05 \mathrm{M}$ potassium (hexa)

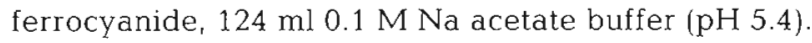
First post-incubation wash in $\mathrm{Na}$ acetate buffer.

Controls. For $\beta$-GPase, CMPase, and TPPase, grids were incubated without substrate, or with $0.05 \mathrm{mM} \mathrm{Na}$ L-tartrate as inhibitor (+ta). Beta-galactosidase was incubated without substrate. Oyster haemocytes served as positive controls. Grids were either examined unstained, or after $5 \mathrm{~min}$ staining with $5 \%$ lead citrate (Pb cit).

Organelle nomenclature is that used earlier (Hine 1991a, 1992, Hine \& Wesney 1992).

\section{RESULTS}

Reaction patterns in Bonamia sp. organelles are given in Table 1 The ZIO technique stained the nuclear membrane (Figs. 1 \& 2), but not nuclear pores (Fig. 3), and stained perinuclear Golgi (Fig. 2), short, meandering (Fig. 1) and large parallel arrays (Figs. 4 \& 5) of smooth endoplasmic reticulum (sER) including sER around haplosporosome-like bodies (Fig. 4). Lipoid bodies (Fig. 5), anastomosing endo-

Figs. 1 to 8. Bonamia sp. Zinc iodide-osmium tetroxide (ZIO) labelling. Fig. 1. A late stage Bonamia sp. with a ZIO-positive nuclear membrane, peripheral endoplasmic retıculum, ER, anastomising ER, aER (arrow), and ER (*) around a lipoid body (L). Pb cit, $\times 16610$. Fig. 2. Portion of parasite showing the nuclear membrane (NM), Golgi (G), aER, ER and lipoid body (LB). Pb cit, $\times 41625$. Fig. 3. Nuclear membrane showing unreactive nuclear pores (arrowheads). Unstained, $\times 44000$. Fig. 4 . Portion of late stage Bonamia sp. showing stacks resembling smooth ER, sER, vesicles (V), haplosporosome-like bodies (HLB), and bizarre membraneous configurations with a ZIO-negative dense lamina between confronting cisternae (arrowhead). Pb cit, $\times 45130$. Fig. 5 . Golgi-like cisternae (G) associated with a lipoid body (LB). Unstained, $\times 55390$. Fig. 6 . aER closely associated with a peripheral reticulated structure (RS). $\mathrm{Pb}$ cit, $\times 72120$. Fig. 7. Putative endocytotic vacuole (E). Note the ruffled parasite surface adjacent to the vacuole, and variability of haplosporosome $(\mathrm{H})$ staining. Pb cit, $\times 52$ 140. Fig, 8 . Multivesicular bodies near the parasite surface. Pb cit, $\times 47080$ 

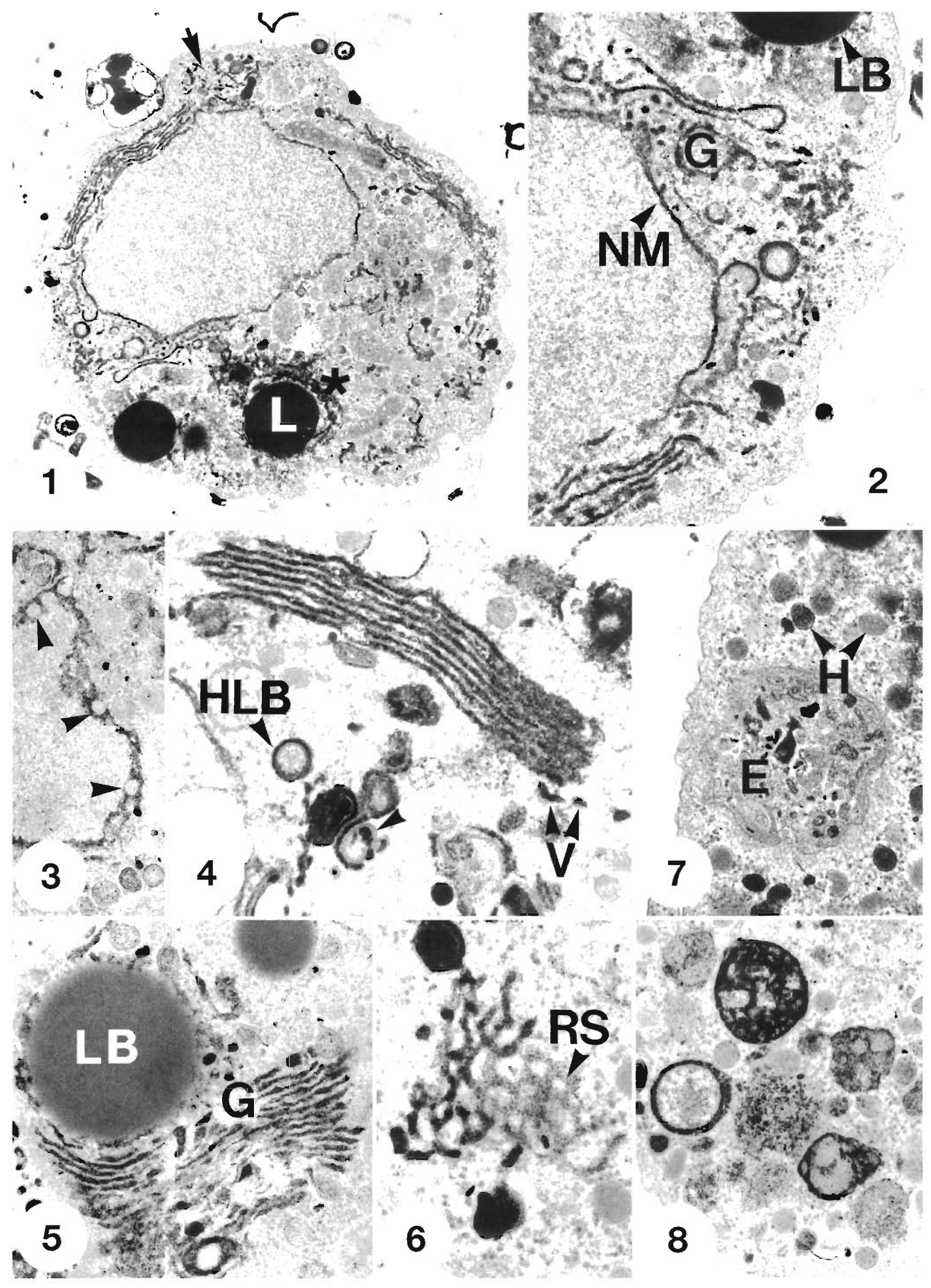

8 
Table 1. Bonamia sp. Cytochemical reactions in organelles. ++ : moderate to strong t: $_{\text {: weak }} \pm$ : variable - : not observed; ta: Ltartrate added as inhıbitor; ns: peripheral Golgi not seen; nd: not determined. For cylochemical abbreviatıons see 'Materials and methods'

\begin{tabular}{|c|c|c|c|c|c|c|c|}
\hline & $\mathrm{ZIO}$ & IM & $\beta$-GPase & CMPase 5.0 & CMPase 2.7 & TPPase & $\beta$-Galactosidase \\
\hline Nuclear membrane & ++ & ++ & ++ ta & - & ++ & - & - \\
\hline Perinuclear Golgi & ++ & \pm & \pm ta & \pm & ++ & \pm & \pm \\
\hline Peripheral Golgi & $+t$ & ++ & ns & ns & ns & ns & ns \\
\hline Endoplasmic reticulum (ER) & ++ & ++ & $++t a$ & \pm & ++ & - & - \\
\hline Anastomosing ER & ++ & + & - & \pm & ++ & - & - \\
\hline Lıpoid bodies & \pm & ++ & + & nd & nd & - & - \\
\hline Haplosporosomes & \pm & + & - & - & - & - & - \\
\hline Mitochondrial membranes & - & ++ & ++ ta & - & - & - & - \\
\hline
\end{tabular}

plasmic reticulum (aER) which appeared to connect to a reticular structure (Fig. 6), cytoplasmic vesicles (Fig. 4), some content of putative endocytotic vacuoles (Fig. 7), the matrix of mitochondria, discreet reticulated structures near the plasma membrane (Fig. 6), and some haplosporosomes (Fig. 7) were also stained. Lipoid bodies (Fig. 1), and multivesicular bodies (MVBs) near the parasite surface (Fig. 8), showed varying degrees of $\mathrm{ZIO}$ reaction. The matrix of $M V B / G o l g i$ complexes, and the dense laminae of confronting cisternae, did not stain with ZIO. Weak labelling of the nuclear membrane, some endoplasmic reticulum (ER), and $s E R$ arrays associated with lipoid bodies was observed in large dense moribund Bonamia sp. in ZIO grids incubated with (control) and without DTT.

Lipids stained most strongly in the lipoid bodies (Fig. 9), but also occurred in the membranes, and as irregularly spaced product in the lumina of nuclear membranes (Fig. 9), some (Fig. 10) but not all (Figs. 9 \& 11) Golgi cisternae, parallel (Fig. 11) and short (Fig. 12) arrays of sER including those associated with lipoid bodies, and in mitochondrial membranes and vesicular cristae (Fig, 12). Lipid deposits were present in the cytoplasm and attached to mitochondrial membranes (Fig, 9), but were particularly apparent within mitochondria (Fig. 12). aER and the surface of some haplosporosomes reacted weakly for lipid (Fig. 12), and membranes in putative phagosomes were moderately to weakly positive (Fig. 13).

Weak $\beta$-GPase activity was seen in a few Bonamia $\mathrm{sp}$. incubated with and without inhibitors, but was absent from most Bonamia sp. and control sections. It was seen in association with membraneous intramitochondrial figures (Fig. 14), and in membraneous vesicles associated with Golgi-like arrays (Fig. 15). Reaction product was not observed within Golgi cisternae, although nuclear membranes and perinuclear Golgi, which are structurally similar (Fig. 16), were well defined in $\beta$-GPase-incubated sections (Figs. $15 \& 16$ ). $\beta$-GPase was most evident in nuclear and mitochon- drial membranes, short profiles of sER, and some Golgi cisternae of cells incubated with tartrate (Fig. 17).

At pH 5.0, CMPase reaction product was observed in some Golgi cisternae (Fig. 18), in some short ER or aER (Fig. 19) and in association with intramitochondrial membranes. Confronting cisternae showed no enzyme activity (Fig. 18). Coarse reaction product occurred over the nucleolus in some Bonamia sp. in sections incubated with and without substrate. Controls and sections incubated with tartrate were negative

At $\mathrm{pH} 2.7 \mathrm{CMPase}$ activity was stronger than at $\mathrm{pH} 5.0$, but there was more non-specific reaction product. CMPase 2.7 occurred over the nucleolus, in the nuclear membrane, in Golgi cisternae (Fig. 20), in looped (Fig. 21) and peripheral sER (Fig. 22), and in aER (Fig. 23). Activity was not observed in lipoid bodies or in intramitochondrial membranes. Controls were negative except for deposits on the nucleus.

Very few Bonamia sp. contained TPPase, and then it occurred very weakly in the lumen of a single Golgi cisterna (Figs. $24 \& 25$ ), and in lipoid bodies and intramitochondrial membranes of a few parasites. Coarse nuclear deposits were common, especially over the nucleolus (Fig. 24). Occasional observation of intracytoplasmic fine granular deposits was associated with apparent endocytosis of haemocyte TPPase by enclosing phagosome contents using short blunt pseudopodia (Fig. 26). Controls were negative, except for coarse nuclear deposits

$\beta$-Galactosidase was rarely observed, and then only as small intracisternal deposits in Golgi (Fig. 27).

\section{DISCUSSION}

The nuclear membrane, sER, Golgi, aER, and MVBs of Bonamia sp. were labelled with ZIO, and may be part of an interconnected system, equivalent to the central vacuolar system in mammalian cells (Klausner 1989). The nuclear membrane and sER resemble the same structures in mammalian cells, but there are 


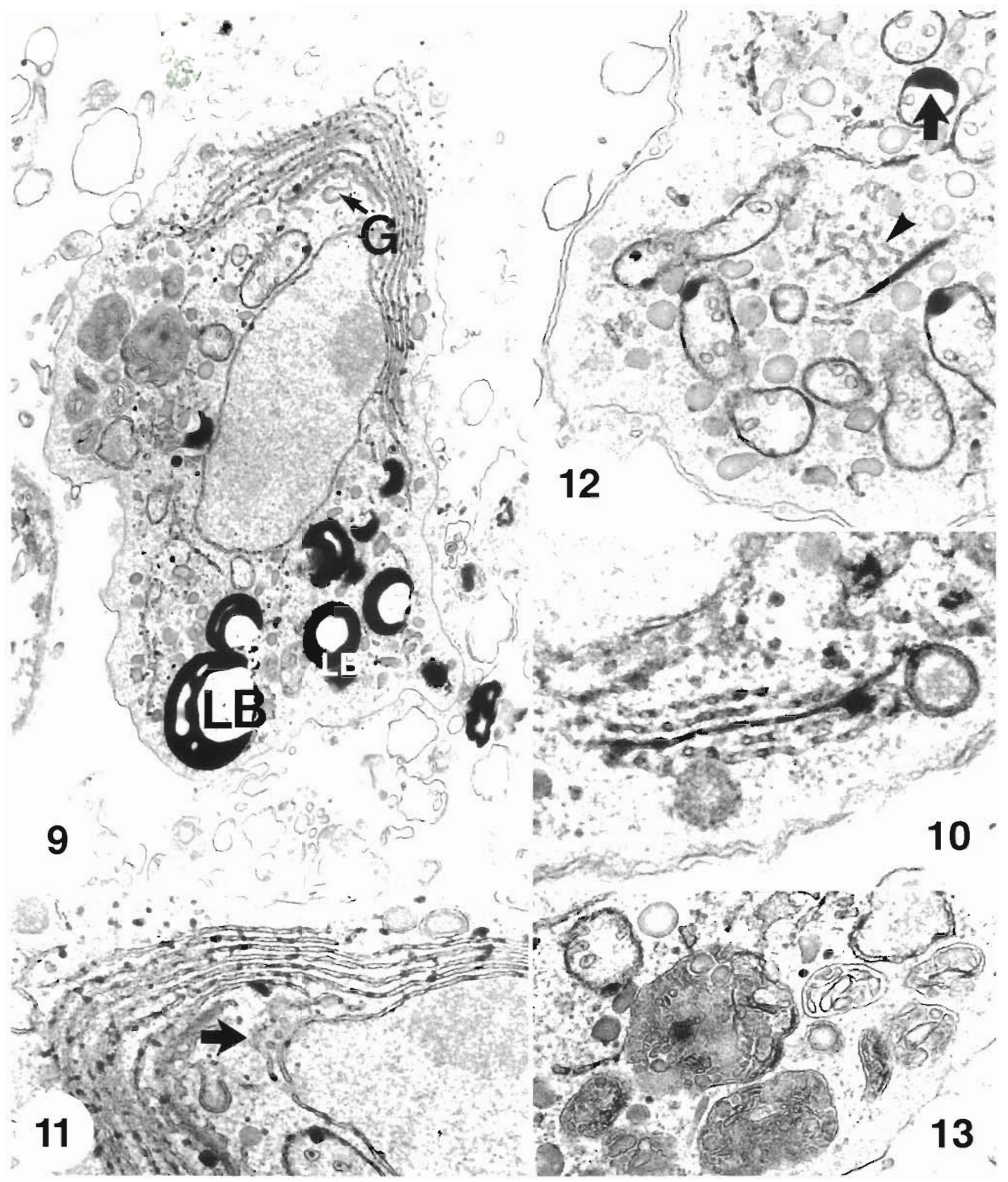

Figs. 9 to 13. Bonamia sp. Imidazole (IM) labelling Fig 9. Late stage Bonamia sp showing lupıd in the lipoid bodıes (LB), peripheral sER-like stacks, mitochondria and therr membranes, but not in Golgl (G) Pb clt, $\times 20130$ Fig. 10 Beaded fenestrated cisternae of perinuclear Golgi with 1 cisterna containıng lıpid Pb cıt, $\times 71190$ Fig. 11 Detall of Fig 9 showing lipıd in perıpheral Golgi-like sER arrays, but absence from Golgı (arrow). Pb cit, $\times 38440$ Fig. 12. Lipid in and on mitochondral membranes (arrow), in vesicular cristae, and short ER, but only weakly in aER (arrowhead). Pb cit, $\times 45000$. Fig 13 Endocytic vacuoles containıng membranes showing moderate to weak reaction for lipid $\mathrm{Pb}$ cit, $\times 46120$ 

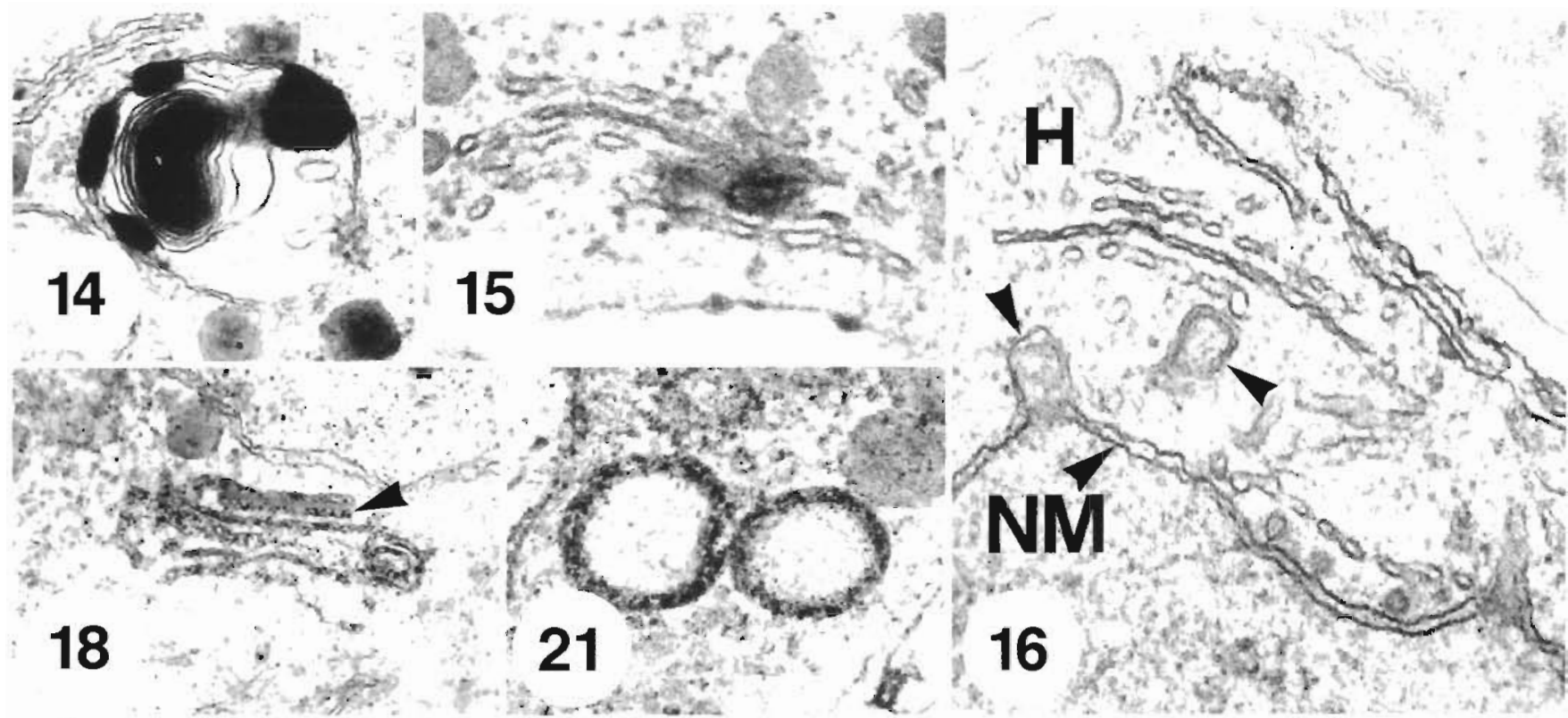
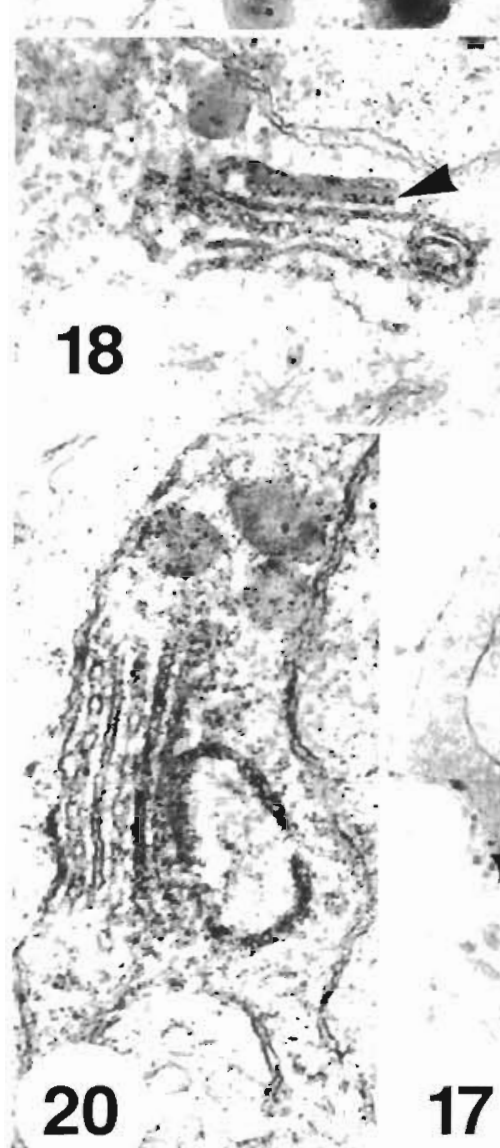
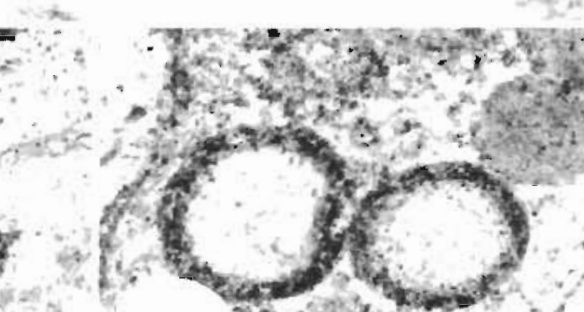

21 x of

h.

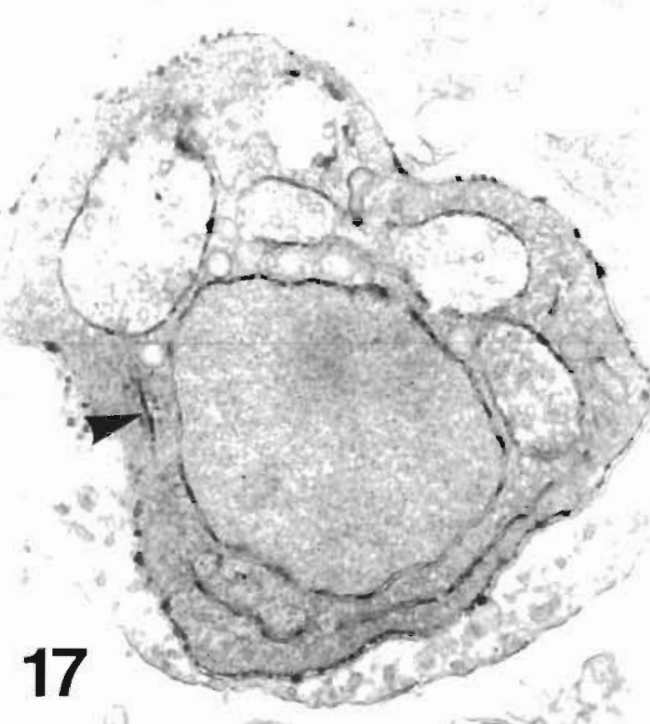

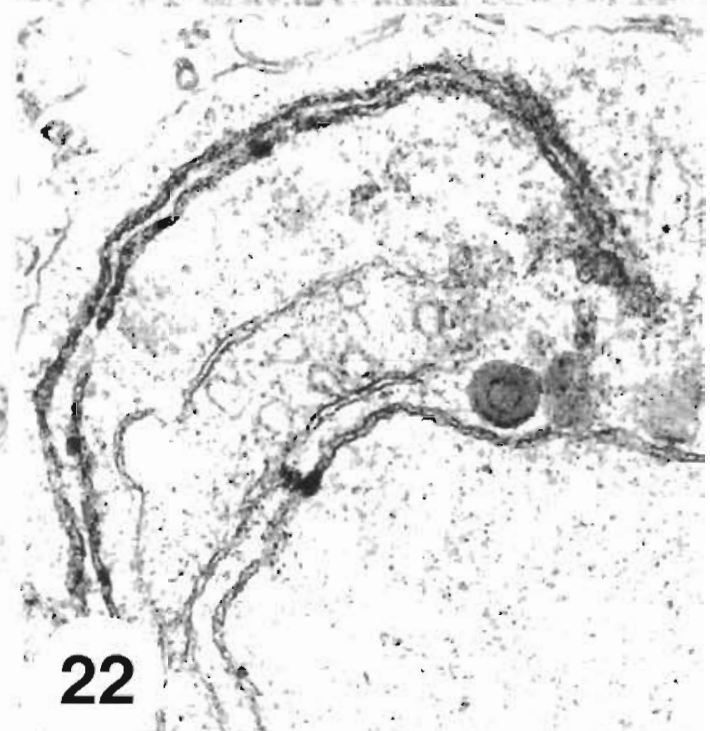

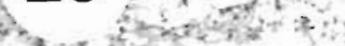

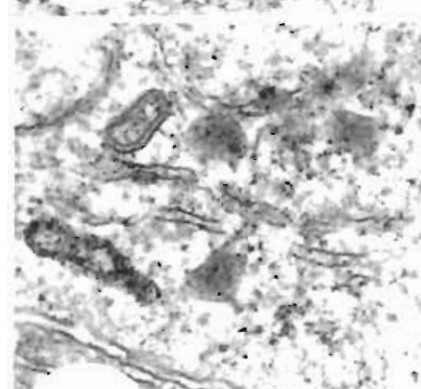$$
19
$$

19 tas $\quad+$

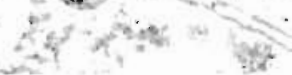

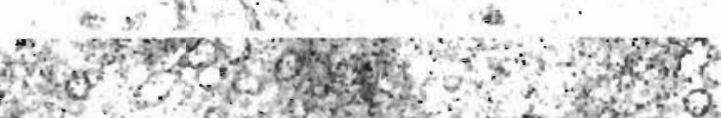

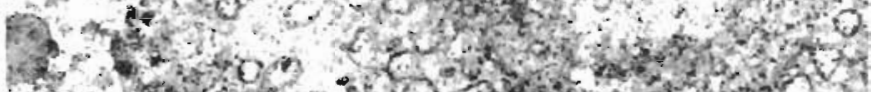

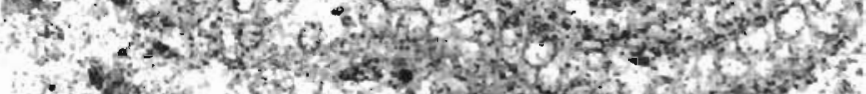

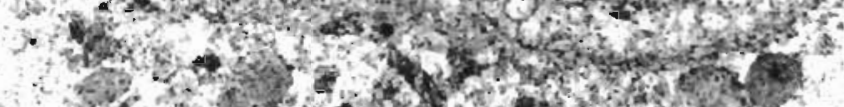

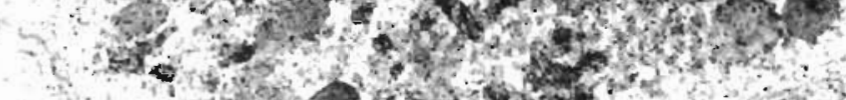
$x^{2}$

23

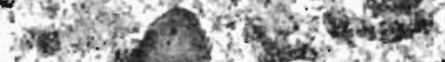

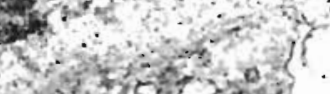


Figs. 14 to 23. Bonamia sp. Acid phosphatases Flg $14 \beta$-GPase reaction product associated with intra-mitochondrial membranes $\mathrm{Pb}$ cit, $\times 54$ 070. Fig. 15. Vesicular $\beta$-GPase activity in perinuclear Golgi Pb cit. $\times 96260$ Fig 16 Enhanced membranes of perlnuclear Golgi and short ER. Note the similanty in beading in the nuclear membrane (NM) and Golgi cisternae, and the apparent budding of the nuclear surface (arrowheads), possibly to form haplosporosomes (H) $\beta$-GPase Pb cit, x67 780. Fig. 17. $\beta$-GPasepositive nuclear, short ER, and mitochondrial membranes, and positive Golgi cisternae (arrowhead) $+\mathrm{ta} \mathrm{Pb}$ cit, $\times 23000$ Fig. 18. CMPase 5.0-positive perinuclear Golgu cisternae. Note the unreactive CC (arrowhead) Pb cit, $\times 50000$. Fig. 19. CMPase 5.0-positive looped ER and aER. Pb cit, $\times 51150$ Fig 20. Perınuclear Golgi showing some positive cisternae CMPase $27 \mathrm{~Pb}$ cit. $\times 61110$. Fig. 21 Positive looped ER. CMPase $2 . \overline{7} \mathrm{~Pb}$ cit. $\times 98230$ Fig. 22 Positive peripheral ER CMPase $27 \mathrm{~Pb}$ cit. $\times 55440$.

Fig. 23. Positive aER CMPase 27 Pb clt, $\times 49940$

several differences between mammalian Golgl, and the Golgi of Bonamia sp. Mammalian Golgı consısts of cis cisternae that receive vesicles from transitional elements of endoplasmic reticulum (Roth 1989); medial cisternae that contain nicotinamide adenine dınucleotide phosphatase activity (Griffiths \& Simons 1986. Roth 1989); and trans cisternae which contain TPPase (Griffiths \& Simons 1986, Roth 1989, Hermo et al. 1991) and sometimes CMPase (Roth 1989, Hermo et al. 1991) The trans cisternae are connected to a trans-tubular or trans-Golgı network of anastomosing tubules connected to the trans cisternae (Roth 1989). containing TPPase and CMPase (Roth et al. 1985. Hermo et al. 1991) from products which are sorted along various pathways (Griffiths \& Simon 1986). Cisternae may be joined by an intercisternal connecting region. The distributions of TPPase and CMPase are varlable depending on the cell type and

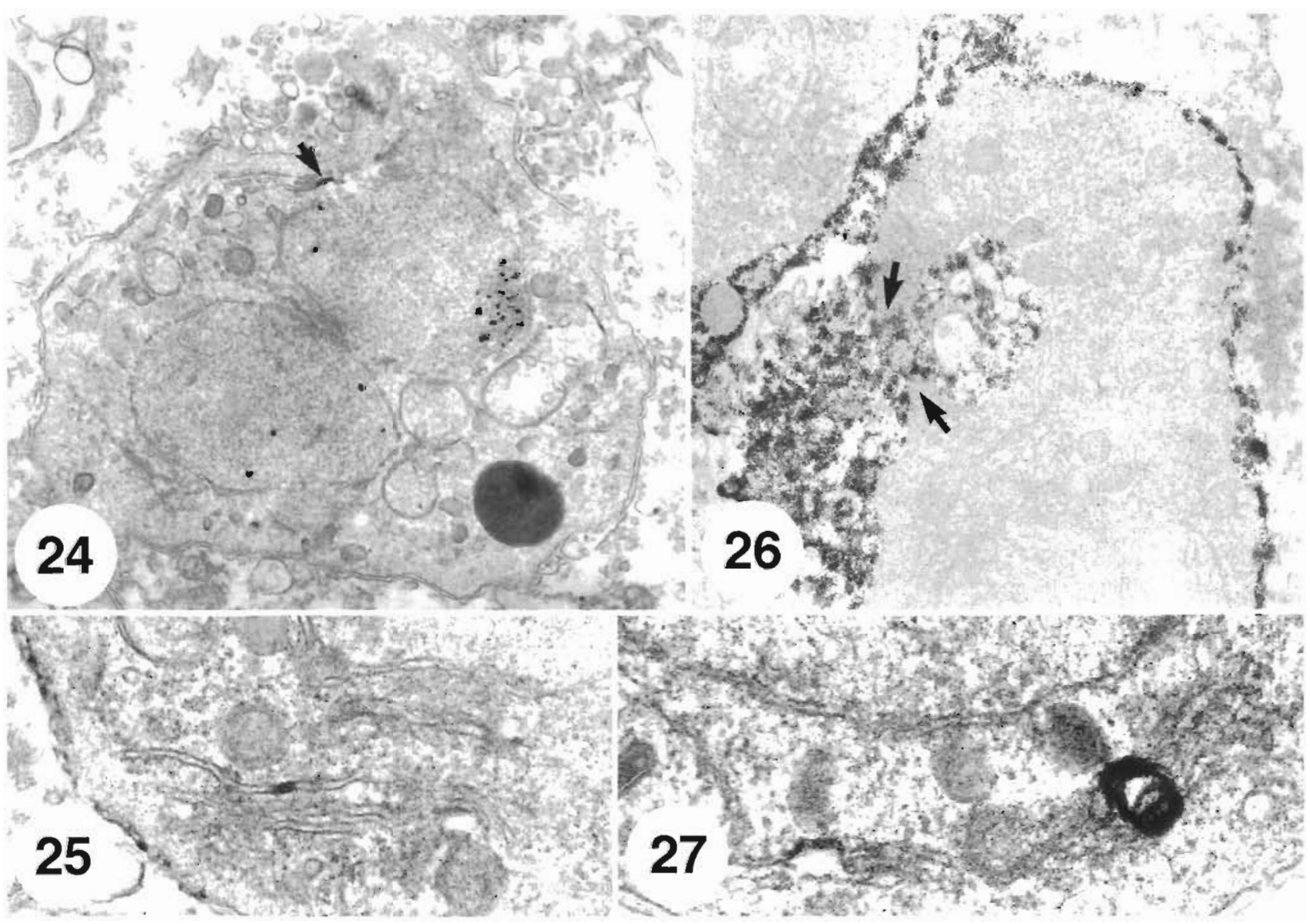

Figs. 24 to 27. Bonamia sp. Fig. 24. TPPase reaction product over the nucleolus and in 1 Golgi cisterna (ariow) Unstained, $\times 22480$. Fig. 25. Reaction product in the lumen of a perinuclear Golgi cisterna TPPase Pb cit, $\times 58750$. Fig. 26 Haemocyte TPPase-positive material being enclosed by 2 lobopodia (arrows) Unstaıned, $\times 42030$ Fig $27 \beta$-Galactosıdase reactıon product in perinuclear Golg1 $\mathrm{Pb} \mathrm{cit}, \times 73610$ 
physiological state of the cell, while lysosomal enzymes may be present throughout the Golgi (Griffiths \& Simon 1986).

Two types of Golgi-like structure occur in Bonamia $\mathrm{sp}$. Perinuclear cisternae are often connected to the nuclear membrane, comprise 3 to 6 (mean $\pm \mathrm{SD}=$ $4.3 \pm 0.9 ; n=68$ ) cisternae some of which may appear beaded or fenestrated (Fig. 10), and participate in the processing of putative nuclear material to form haplosporosome-like bodies (Hine 1992, Hine \& Wesney 1992). Sometimes the adjacent nuclear membrane is also beaded, and haplosporosome-like bodies appear to bud off from the nuclear membrane (Fig. 16). Perinuclear Golgi differs morphologically from the Golgi of higher animals in the uniformity of cisternae, the absence of vesicles budding from the ends of cisternae, and lack of budding of coated or uncoated vesicles containing protein from trans cisternae or transtubular networks. The second Golgi-like structure comprises large arrays in the peripheral cytoplasm of plasmodial forms (Hine 1991a) that may resemble sER (Figs. 4 \& 11) (Hine 1992) or cisternae (Fig. 5) and are often seen enclosing or near lipoid bodies (Hine 1992).

Other protistans show a range of Golgi morphologies, that range from similarity to the Golgi of higher animals (Queiroz et al. 1991, Vickerman et al. 1991) to endoplasmic reticulum budding coated or uncoated vesicles (Lobo-da-Cunhá \& Azevedo 1990, Palluault et al. 1990), reticulated tubular structures (Desportes 1976, Lom et al. 1983), or a few small cisternae (Langreth et al. 1978, Kurz \& Tiedtke 1993) similar to the perinuclear arrays in Bonamia sp. (Hine \& Wesney 1992). Giardia lamblia forms secretory vesicles from $E R$ in nuclear membrane indentations, as in Bonamia sp. perinuclear complexes (Hine \& Wesney 1992), but acid phosphatase derives from multiple Golgi-like cisternae (Reiner et al. 1990) similar to arrays in Bonamia sp. peripheral cytoplasm (Fig. 5). In Plasmodium spp. the ER is dispersed in young stages but forms ordered parallel arrays in older stages (Slomianny \& Prensier 1990). Unlike mammalian Golgi, in which the cis face stains with ZIO (Parmley et al. 1988), the Golgi of protistans (Benchimol \& de Souza 1985 , Slomianny \& Prensier 1990) and protist-like organisms (Palluault et al. 1990) show variable or overall ZlO staining of Golgi. The similar distribution of ZIO reaction in moribund Bonamia sp. incubated with (control) and without DTT, suggests DTT does not inhibit ZIO staining, as was also observed in Pneumocystis carinii by Palluault et al. (1990).

Apparently Bonamia sp. has a system comprising the nuclear membrane, sER, aER, and Golgi-like arrays that may be perinuclear or cytoplasmic, which are involved in lipid and enzyme production and processing. The system appears to be poorly differentiated morphologically, as perinuclear Golgi appears little modified from the nuclear membrane (Fig. 16) and parallel Golgi-like arrays resemble sER (Fig. 4). There was no evidence of enzyme partitioning or functional polarity in perinuclear Golgi cisternae, and in a previous study (Hine 1992) osmium impregnation did not distinguish a cis face, as it does in mammalian cells (Tang \& Clermont 1989). Compared with some other protistans, the Golgi-endoplasmic reticulum complex appears primitive, both in structure (Vickerman et al. 1991) and function (Langreth \& Balber 1975, Queiroz et al. 1991, Kurz \& Tiedtke 1993).

Enzymatic activity within protists may depend on activation and the stage of the life-cycle (Reiner et al. 1990, Pimenta et al. 1991), and this must be taken into account when assessing reactivity. Even taking this into account, at normal incubation $\mathrm{pH}$, acid phosphatases ( $\beta$-GPase, CMPase 5.0, TPPase) and $\beta$-galactosidase were often only weakly present or limited in distribution in Bonamia sp. CMPase 5.0, TPPase, and $\beta$-GPase did not show selective reaction in cisternae of 1 face of Golgi to suggest the existence of cis and trans faces, although too few observations were made on TPPase to determine such a polarity. It was difficult to assess the degree of reaction of lipoid bodies because of their density, but some may have contained very weak CMPase 5.0 and weak to moderate $\beta$-GPase.

Several other protistans also do not have enzyme content suggesting functional polarity of the Golgi (Pimenta \& de Souza 1986, Soares \& de Souza 1988, Lobo-da-Cunha \& Azevedo 1990, Reiner et al. 1990, Slomianny \& Prensier 1990). For example CMPase could not be detected by Palluault et al. (1990) in the Golgi of Pneumocystis carinii. However, in Trypanosoma brucei the Golgi trans face is distinguished by $\beta$-GPase (Langreth \& Balber 1975), in Tetrahymena thermophilia the trans Golgi is labelled by $\beta$-GPase and TPPase (Kurz \& Tiedtke 1993), and in Tritrichomonas foetus CMPase labels the trans face, while TPPase labels the cis face (Queiroz et al. 1991). At normal incubation $\mathrm{pH}$ the acid phosphatase content of Bonamia sp. ER was also weak when compared to other protistans (Pimenta \& de Souza 1986, Feely \& Dyer 1987, Soares \& de Souza 1988, Reiner et al. 1990, Slomianny \& Prensier 1990).

At $\mathrm{pH}$ 2.7, CMPase was observed in the same structures (nuclear membrane, sER, Golgi, aER) as ZIO, which probably comprise a system equivalent to the central vacuolar system of mammalian cells. The intensity of labelling was stronger than for other enzymes, but in the absence of lysosomes or staining of vesicles or lipoid bodies, there was no apparent storage of the enzyme. Although Hervio et al. (1991) suggested acid 
phosphatase may be used to coat and protect the plasma membrane as in Leishmania spp., there was no evidence of an acid phosphatase surface coat herein. The substance coating Leishmania spp. has now been identified as lipophosphoglycan (LPG) which is formed from acid phosphatase in the Golgi by the addition of a carbohydrate structure (Bates et al. 1990).

Bonamia sp. grows and divides inside haemocytes, and therefore it must endocytose material. As Bonamia $\mathrm{sp}$. in parasitophorous vacuoles (PVs) are often surrounded by membraneous particles, the MVBs observed in Bonamia sp. in this (Figs. $8 \& 9$ ) and a previous study (Figs. 22 \& 23 in Hine \& Wesney 1992) may result from pinocytosis or phagocytosis. Ultrastructurally the MVBs of Bonamia sp. resemble the MVBs of Trypanosoma cruzi that form from fusion of pinocytotic vesicles and which are involved in protein uptake (de Souza et al. 1978, Soares \& de Souza 1988). If the MVBs in Figs. 22 \& 23 of Hine \& Wesney (1992) do result from endocytosis, the close apposition of MVBs and Golgi in Fig. 23 suggests that Golgi-derived vesicles containing hydrolytic enzymes may fuse directly with endocytotic MVBs, rather than first forming a lysosome that then fuses with the MVB. Some acid phosphatase may be stored in lipoid bodies, but there was no apparent interaction between endocytotic MVBs and lipoid bodies.

Intense IM staining of the lipoid bodies indicates that this organelle, which lacks a bounding membrane, has a high lipid content. The presence of lipid in the lumina of the nuclear membranes, some perinuclear Golgi cisternae, and ER suggests that lipid is processed through these compartments, although aER appeared to be less involved in lipid processing. There was a close association between lipid-rich sER arrays (Fig. 11) and lipoid bodies (Fig. 5), similar to the association between ER arrays and lipid bodies in Leishmania (Pimenta \& de Souza 1986) and other trypanosomatids (Soares \& de Souza 1988). Staining with IM also indicated that mitochondria may act as a centre for lipid synthesis or storage, as in some other protists (Zierdt et al. 1988).

Lipoid bodies may function in 1 or more of 4 different ways. (1) They may be storage organelles for excess triglycerides. As IM binds to unsaturated lipids such as triglycerides (Angermüller \& Fahimi 1982), lipoid bodies probably have a high unsaturated lipid content. During the annual infection cycle of the parasite in oysters (Hine 1991a, b) Bonamia sp. proliferates and grows (Hine 1991a) in haemocytes that re-absorb unspawned oyster ova (Hine 1991b). Oyster ova are rich in triglycerides (Lee \& Heffernan 1991) and at the time of ova reabsorption lipoid bodies and large sER arrays develop in the parasite (Hine 1991a). Lipoid bodies may therefore be stores of triglycerides derived from host ova and other cells and may be an energy reserve for the parasite.

(2) Lipoid bodies may be involved in lipid secretion or excretion. In phagocytosis, Bonamia ostreae suppresses the haemocyte respiratory burst (Hervio 1992) and, like Bonamia sp., comes to lie in a PV. Some apicomplexan protozoans that utilize phagocytes discharge lipid-like vesicles that enlarge the phagosome membrane to produce a PV, and modify it to prevent lysosome-phagosome fusion (Sibley 1989). Thus lipoid bodies in Bonamia spp. may discharge similar vesicles to modify the host phagosome membrane, form the PV, and prevent lysosome-phagosome fusion.

(3) Contrary to a previous study (Hine 1992), lipoid bodies appeared to contain some $\beta$-GPase, occasional very weak TPPase, and possibly some CMPase 5.0. Hervio et al. (1991) observed CMPase in lipoidal bodies of Bonamia ostreae. In Leishmania mexicana amazonensis the ER around lipoid bodies contains $\beta$-GPase (Fig. 5 in Pimenta \& de Souza 1986). The lipoidal body may therefore be a lipolysosome that participates in cellular defence or digestion.

(4) Unsaturated lipids may, as in Leishmania spp., scavenge $\mathrm{H}_{2} \mathrm{O}_{2}$ generated as a killing mechanism by host haemocytes (Channon \& Blackwell 1985).

The main function of lipoid bodies is probably lipid metabolism based on triglycerides, as lipid metabolism may explain both the presence of confronting cisternae (CC) and cylindrical confronting cisternae (CCC) in some Bonamia late in the infection cycle (Hine \& Wesney 1992), and the weak hydrolytic enzymes. Unusual membraneous structures, including some resembling $\mathrm{CCC}_{1}$ are formed in fish enterocytes involved in lipid metabolism (Ostos Garrido et al. 1993). In vertebrates, lipids are hydrolysed extracellularly by pancreatic lipase, combine with bile to form micelles that diffuse through the plasma membrane, and are re-synthesised intracellularly as triglycerides. Haemocytes may hydrolyse triglyceride-rich cytosol from ova before or after endocytosis, making breakdown products directly available to the parasite. Direct utilisation of fatty acids and glycerol from haemocytes, and their re-synthesis into triglycerides within the parasite, would negate the need for a well-developed lysosomal system storing hydrolytic enzymes in Bonamia sp., and would involve mitochondria in triglyceride re-synthesis, as suggested from enzyme and IM reaction observed herein. Utilisation of lipids by the parasite would also explain the lack of intracellular glycogen or other carbohydrate reserve. The presence of CC, CCC, haplosporosome-like bodies, and bizarre membraneous configurations in Bonamia sp. late in the annual infection cycle (Hine \& Wesney 1992) may therefore be attributable to breakdown of lipid metabolism due to parasite senescence. 
Acknowledgements. We are grateful to Karen Reader, Rob Thomson, and Teeba Lundy of the Electron Microscope Facility, Victoria University of Wellington, for their technical assistance.

\section{LITERATURE CITED}

Angermüller, S., Fahim, H. D. (1982). Imidazole-buffered osmium tetroxide: an excellent stain for visualization of lipids in transmission electron microscopy. Histochem. J. $14: 823-835$

Azevedo, C. Corral. L. (1985). Cytochemical analysis of the haplosporosomes and vesicle-like droplets of Haplosporidium lusitanicum (Haplosporida, Haplosporidiidae), parasite of Helcion pellucidus (Prosobranchia). J. Invertebr. Pathol. 46: $281-288$

Bates, P. A., Hermes, I., Dwyer, D. M. (1990). Golgi-mediated post-translational processing of secretory acid phosphatase by Leishmania donovani promastigotes. Molf.c. Biochem. Parasitol. 39: 247-256

Benchimol, M., de Souza, W. (1985). Tritrichomonas foetus: cytochemical visualization of the endoplasmic reticulumGolgi complex and lipids. Exp. Parasitol. 59: 51-58

Channon, J. Y., Blackwell, J. M. (1985). A study of the sensitivity of Leishmanid donovani promastigotes and amastigotes to hydrogen peroxide. II. Possible mechanisms involved in protective $\mathrm{H}_{2} \mathrm{O}_{2}$ scavenging. Parasitology 91: 207-217

de Souza, W., de Carvalho, T U., Benchimol, M. (1978). Trypanosoma cruzi: ultrastructural cytochemical and freeze-fracture studies of protein uptake. Exp. Parasitol. 45: $101-115$

Desportes, I. (1976). Ultrastructure de Stempellia mutabilis Leger et Hesse, microsporidie parasite de l'Éphémère, Ephemera vulgata L. Protistologica 12: 121-150

Desportes, 1., Nashed, N. N. (1983). Ultrastructure of sporulation in Minchinia dentali (Arvy), an haplosporean parasite of Dentalium entale (Scaphopoda, Mollusca); taxonomic implications. Protistologica 19: 435-460

Feely, D. E., Dyer, J. K. (1987), Localization of acid phosphatase activity in Giardia lamblia and Glardia muris trophozoites. J. Protozool. 34: 80-83

Griffiths, G., Simons, K. (1986). The trans Golgi network: sorting at the exit site of the Golgl complex. Science 234: $4.38-4.43$

Hermo, L., Green, H., Clermont, Y (1991). Golgi apparatus of epthelial principal cells of the epididymal initial segment of the rat: structure, relationship with endoplasmic reticulum, and role in the formation of secretory vesicles. Anat. Rec. 229: 159-176

Hervio, D. (1992). Contribution à l'étude de Bonamia ostreae (Ascetospora), protozoaire parasite de l'huitre Ostrea edulis (Bivalvia), et à l'analyse des interactions hôteparasite. Thèse, Université Blaise Pascal, ClermontFerrand

Hervio, D., Chagot, D., Godin, P., Grizel, H., Mialhe, E. (1991). Localization and characterization of acid phosphatase activity in Bonamia ostreae (Ascetospora), an intrahemocytic protozoan parasite of the flat oyster Ostrea edulis (Bivalvia). Dis, aquat. Org. 12:67-70

Hine, P. M. (1991a). Ultrastructural observations on the annual infection pattern of Bonamia sp. in flat oysters Tiostrea chilensis. Dis. aquat. Org. 11: 163-171

Hine, P. M. (1991b). The annual pattern of infection by Bonamia sp. in New Zealand flat oysters, Tiostrea chilensis. Aquaculture 93: 241-251
Hine, P. M. (1992). Ultrastructural and ultracytochemical observations on Bonamia sp. in oysters (Tiostrea chilensis) with a consideration of organelle function. Aquaculture 107: $175-183$

Hine, P. M., Wesney, B. (1992). Interrelationships of cytoplasmic structures in Bonama sp. (Haplosporidia) infecting oysters Tiostrea chilensis: an interpretation. Dis aquat. Org. 14:59-68

Klausner, R. D. (1989). Sorting and traffic in the central vacuolar system. Cell 57: 703-706

Kornfeld, S., Mellman, I. (1989). The biogenesis of lysosomes A. Rev. Cell Biol. 5: 483-525

Kurz, S. Tiedtke, A. (1993). The Golgi apparatus of Tetrabymena thermophila. J. eukaryot. Microbiol. 40: 10-13

Langreth, S. G., Balber, A. E. (1975). Protein uptake and digestion in bloodstream and culture forms of Trypanosoma brucei. J. Protozool. 22: 40-53

Langreth, S. G., Jensen, J. B., Reese, R. T., Trager, W. (1978). Fine structure of human malaria in vitro. J. Protozool. 25: $443-452$

Lee, R. F., Heffernan, P. B. (1991). Lipids and proteins in eggs of eastern oysters (Crassostrea virginica (Gmelin, 1791)) and northern quahogs (Mercenaria mercenaria (Linnaeus, 1758)I. J. Shellfish Res. 10: 203-206

Lobo-da-Cunha, A., Azevedo, C. (1990). Enzyme cytochemistry of the alveolar sacs and Golgian-like cisternae in the ciliate Ichthyophthirius multifilis. J. Protozool. 37: $206-211$

Lom, J., Dykova, I., Pavlaskova, M. (1983). 'Unidentified' mobile protozoans from the blood of carp and some unsolved problems of myxosporean life cycles. J. Protozool. 30: $497-508$

Ostos Garrido, M. V., Núñez Torres, M. V., Abaurrea Equisoain, M. A. (1993). Lipid absorption by enterocytes of the rainbow trout, Oncorhynchus mykiss; diet-induced changes in the endomembranous system. Aquaculture 110: $161-171$

Pallault, F, Dei-Cas, E., Slomianny, C., Soulez, B., Camus, D. (1990). Golgi complex and lysosomes in rabbit derived Pneumocystis carinii. Biol. cell. 70: 73-82

Parmley, R. T., Kinkade, J. M., Akin, D. T., Gilbert, C. S., Guzman, G. S. (1988). Monensin disruption of neutrophil granule genesis. Am. J. Pathol. 133: 537-548

Pellegrino de Iraldi, A. (1977). Significance of the maillet method (ZIO) for cytochemical study of subcellular structures. Experimentia 33: 1-10

Perkins. F. O. (1976). Ultrastructure of sporulation in the European flat oyster pathogen, Martellia refringens - taxonomic implications. J. Protozool. 23: 64-74

Perkins, F O. (1979). Cell structure of shellfish pathogens and hyperparasites in the genera Minchinla, Urosporidium, Haplosporidium and Marteilia - taxonomic implications. Mar. Fish. Rev. 41 (Jan-Feb): 25-37

Pimenta, P. F P., de Souza, W. (1986). Cytochemical localization of acid phosphatase in Leishmania mexicana amaronensis. J. submicrosc. Cytol. 18: 127-132

Pimenta, P. F. P., Saraiva, E. ... B., Sacks, D. L. (1991). The comparative fine structure and surface glycuconjugate expression of three life stages of Leishmania major. Exp. Parasitol 72: 191-204

Queiroz, R. C. B., Silva Santos, L. M., Benchimol, M., de Souza, W. (1991). Cytochemical localization of enzyme markers in Tritrichomonas foetus. Parasitol. Res. 77: 561-566

Reiner, D. S., McCaffery, M., Gillin, F. D. (1990). Sorting of cyst wall proteins to a regulated secretory pathway during differentiation of the primitive eukaryote, Giardia lamblia. Eur. J. Cell Biol. 53: 142-153 
Rhodes, J. M., Blom, J. (1986). Cytochemical localization of $\beta$-galactosidase in resident and inflammatory peritoneal macrophages from C57BL mice. Histochemistry 86: $159-164$

Robinson, J. M., Karnovsky, M. J. (1983). Ultrastructural localization of several phosphatases with cerium. J. Histochem. Cytochem. 31: 1197-1208

Roth, J. (1989). Subcellular organization of glycosylation in mammalian cells. Biochim. Biophys. Acta 906: 405-436

Roth, J., Taatjes, D. J., Lucocq, J. M., Weinstein, J., Paulson, J. C. (1985). Demonstration of an extensive trans-tubular network continuous with the Golgi apparatus stack that may function in glycosylation. Cell 43: 287-295

Sibley, L. D. (1989). Active modification of host cell phagosomes by Toxoplasma gondii. In: Moulder, J. W. (ed.) Intracellular parasitism. CRC Press, Boca Raton, FL, p. 245-257

Responsible Subject Editor: A. K. Sparks, Seattle, Washington, USA
Slomianny, C., Prensier, G. (1990). A cytochemical ultrastructural study of the lysosomal system of different species of malaria parasites. J. Protozool. 37: 465-470

Soares, M. J., de Souza, W. (1988). Cytoplasmic organelles of trypanosomatids: a cytochemical and stereological study. J. Submicrosc. Cytol. Pathol. 20: 349-361

Tang, X. M., Clermont, Y. (1989). Granule formation and polarity of the Golgi apparatus in neutrophil granulocytes of the rat. Anat. Rec. 223: 128-138

Vickerman, K., Brugerolle, G., Mignot, J.-P. (1991). Mastigophora. In: Harrison, F. W., Corliss, J. O (eds.) Microscopic anatomy of invertebrates, Vol. 1, Protozoa. Wiley-Liss, New York, p. 13-159

Zierdt, C. H., Donnolley, C. T., Muller, J., Constantopoulos, G (1988). Biochemical and ultrastructural study of Blastocystis hominis. J. clin. Microbiol. 26: 965-970

Manuscript first received: September 27, 1993

Revised version accepted: August 22, 1994 